\title{
Very-high-dose olanzapine for treatment-resistant schizophrenia
}

\author{
Jean-Marie Batail ${ }^{1,2^{*}}$, Sophie Bleher ${ }^{1}$, Clément Lozachmeur ${ }^{1,2}$, Gabriel Robert ${ }^{1,2}$, Bruno Millet ${ }^{1,2}$, \\ Dominique Drapier ${ }^{1,2}$ \\ ${ }^{1}$ Adult Psychiatry Department, Guillaume Régnier Hospital, Rennes, France \\ ${ }^{2}$ Behavior and Basal Ganglia Unit, Rennes University Hospital, University of Rennes I, Rennes, France \\ Email: ${ }^{*}$ jeanmariebatail@,gmail.com
}

Received 25 June 2012; revised 27 July 2012; accepted 6 August 2012

\begin{abstract}
Treatment-resistant schizophrenia has an extremely negative impact on mental health and social life. If clozapine, the gold standard treatment, fails, there are very few options left. The literature suggests that high-dose olanzapine (20 - $60 \mathrm{mg} / \mathrm{day})$ is a possible alternative. We report two cases in which very high doses of olanzapine were administered, with significant clinical improvements above $60 \mathrm{mg} / \mathrm{day}$. Clinical, metabolic and cardiac tolerance was good. This report highlights the usefulness of very-high-dose olanzapine in treatment-resistant schizophrenia. The main hypotheses concerning the psychopharmacological mechanisms of very-high-dose olanzapine are discussed.
\end{abstract}

Keywords: Schizophrenia; Treatment Resistance; High-Dose Olanzapine; Treatment Tolerance

\section{INTRODUCTION}

According to Kane's criteria (1988), treatment-resistant schizophrenia is defined as clinical resistance (PANSS decrease of less than $20 \%$ ) after the administration of three antipsychotic drugs from at least two different chemical classes at optimum doses and over sufficiently long periods.

Clozapine is currently the gold standard treatment for refractory schizophrenia [1,2]. Nevertheless, its prescription sometimes has to be stopped due to either lack of efficacy or intolerance (agranulocytosis). If clozapine fails, there are few treatment options left, although treatment-resistant delusions appear to be alleviated by electroconvulsive therapy, and refractory auditory hallucinations by transcranial magnetic stimulation of the temporoparietal junction [2]. Over the past few years, several studies and case reports have identified high-dose

${ }^{*}$ Corresponding author. olanzapine ( $>20 \mathrm{mg} /$ day) as a pharmacological alternative to clozapine. We report two cases illustrating the usefulness of very high doses $(\geq 60 \mathrm{mg}$ /day) of olanzapine in the management of treatment-resistant schizophrenia.

\section{CASE STUDY 1}

Mr. A, currently aged 29 years, was diagnosed with schizophrenic disorder in 2003. There was no family history of schizophrenia. Most of his hospitalizations were due to severe positive symptoms. A set of crystallized delusions with religious or esoteric themes interfered with the patient's ability to lead a normal everyday life. Auditory and cenesthesic hallucinations were frequent. Between 2004 and 2006, there were many hospitalizations owing to behavioral problems associated with delusions. Many antipsychotics were tried at adequate doses over sufficiently long periods, including pipotiazine, risperidone (depot form), olanzapine $(20 \mathrm{mg}$ ), haloperidol (depot form), aripiprazole, amisulpride and zuclopenthixol (depot form). All these medications had to be stopped, either because of their lack of efficacy in treating refractory hallucinations or because of intolerance (extrapyramidal syndrome). Electroconvulsive therapy was prescribed with good results, but the effect could not be maintained over time. In 2008, clozapine was prescribed. Reduced delusions, better conceptual organization and improved social relations were observed. Unfortunately, 11 months later, the patient had a bout of fever with agranulocytosis, which meant that the clozapine had to be stopped. He was hospitalized due to a fresh upsurge of delusions and hallucinations.

In this context, it was decided to gradually introduce high-dose olanzapine. Clinical (monthly weight and waist measurements), biological (monthly blood lipid and glucose tests, weekly blood counts) and electrocardiogram (weekly) monitoring was performed. No clinical effects were observed up to $60 \mathrm{mg}$ /day (administered three times per day). From $80 \mathrm{mg} /$ day, however, positive 
symptoms such as delusions, hallucinations and behavioral problems decreased. Although the dose was increased to $100 \mathrm{mg} /$ day, we failed to observe any significant improvements in negative symptoms, such as impaired social relations or emotional withdrawal. Clinical tolerance was good, and no side effects (e.g., extrapyramidal syndrome, weight gain) were reported. Biologically, a slight neutropenia $\left(1300-1700 / \mathrm{mm}^{3}\right)$ was recorded over a 6-week period, but it was well tolerated. After three months of treatment at $100 \mathrm{mg} /$ day, the blood lipid level was slightly increased for cholesterol (6.3 $\mathrm{mmol} / \mathrm{l})$, but was still normal for triglycerides $(0.52$ $\mathrm{mmol} / \mathrm{l}$ ). No normalization was observed during the patient's hopitalization. Blood sugar level have been checked and was normal, no glycosylated hemoglobin have been assessed. Olanzapine blood level was 197.2 $\mathrm{ng} / \mathrm{ml}$. Mr. A's improved clinical condition has remained stable since 2009. He completed a psychosocial rehab program and has not been hospitalized for two years.

\section{CASE STUDY 2}

Mr. B, currently aged 21 years, experienced early-onset schizophrenia. His first schizophrenic symptoms appeared at around the age of 14 years. He developed persecutive, intuitive and interpretative delusions. The functional impact on his work and social relations was massive and forced him to quit secondary school. No auditory hallucinations were ever described. The main symptoms were psychic, affective and behavioral disorganization, probably masking the previously reported delusions. He was treated with risperidone, first in its oral form, then in its depot one $(50 \mathrm{mg} / 2$ weeks $)$. He received this treatment for two years, but then returned to hospital due to an acute episode. During a 7-month hospitalization, zuclopenthixol, aripiprazole, and haloperidol were successsively tried at adequate doses and over sufficiently long periods without any significant clinical improvement. In this case of resistant early-onset schizophrenia, we decided to try an alternative to clozapine for this young man. Treatment with high-dose olanzapine was thus begun. No effect on the positive and disorganization symptoms was observed until the dose reached $70 \mathrm{mg} /$ day. After three weeks at $80 \mathrm{mg} / \mathrm{day}$, an improvement in the persecutory ideas and a reduction in hostility were observed. After six weeks, remission was diagnosed, despite two residual symptoms (i.e., apragmatism and apathy). Following his 7-month hospitalization, Mr. B joined a psychosocial rehab program. After six months of treatment at $80 \mathrm{mg} /$ day, the patient had gained $10 \mathrm{~kg}$, but his weight remained stable thereafter. Biological tolerance remained good (cholesterol $=4.82 \mathrm{mmol} / \mathrm{l}$, triglycerides $=1.59 \mathrm{mmol} / \mathrm{l}$, glycosylated hemoglobin $=5.7 \%$ $5.9 \%$ ). Olanzapine blood level was $106 \mathrm{ng} / \mathrm{ml}$.

\section{DISCUSSION}

As far as we know, these are the first two reports of olanzapine administration at doses higher than $60 \mathrm{mg}$ /day. Olanzapine is an atypical antipsychotic, with a pharmacological structure close to that of clozapine. Olanzapine shares several aspects of clozapine's in vivo pharmacological profile, including a high affinity for 5-HT2, muscarinic and histamine receptors [3]. Its 5-HT2A antagonism is associated with fewer extrapyramidal symptoms and less tardive dyskinesia than other antipsychotics, thus allowing high doses to be administered [4].

To our knowledge, there have been no controlled studies of such high doses of olanzapine in treatment-resistant schizophrenia, and only a handful of case reports have been published on doses of olanzapine between 20 and $60 \mathrm{mg}$. Sheitman et al. reported a lack of efficacy for positive symptoms, but with doses below $60 \mathrm{mg} /$ day [5]. Other reports have indicated an improvement in social functioning and cognition, and decreased auditory hallucinations at 40 and $50 \mathrm{mg} / \mathrm{day}$ [6,7]. All reports have emphasized its good tolerance. There are conflicting data concerning the relative efficacy of high-dose olanzapine compared with clozapine in treatment-resistant schizophrenia. Some randomized, double-blind studies have demonstrated the superiority of clozapine in refractory, early-onset schizophrenia [8], whereas others have found no difference at all between the two [1,9]. Prospective studies have shown that olanzapine at doses of $15-60$ $\mathrm{mg} /$ day is a good alternative to clozapine for treatmentresistant patients [10-13]. The clinching argument for switching from clozapine to olanzapine is the latter's tolerability.

The present case report also highlights the question of the link between clinical response and olanzapine blood level. Why did these two treatment-resistant patients display a clinical improvement at very high doses despite resistance at low doses of olanzapine? There are divergent data about the relationship between clinical response and olanzapine plasma concentration. Perry et al. suggested that a minimum concentration of $23 \mathrm{ng} / \mathrm{ml}$ was needed to be effective, but did not draw any link with improvements in BPRS scores [14]. Mauri et al. described a curvilinear relationship with clinical efficacy between 20 and $50 \mathrm{ng} / \mathrm{ml}$ of olanzapine serum concentration [15]. Lane et al., however, failed to establish any correlation between olanzapine blood level and improvements in schizophrenic symptoms, although they did find one for depressive symptoms, with a plasma concentration of $36 \mathrm{ng} / \mathrm{ml}$ being a good predictor of response [16]. We can hypothesize that olanzapine's serotonin antagonism plays a key role in the antidepressant effect.

Finally, at doses of $5-40 \mathrm{mg} / \mathrm{d}$, striatal dopamine D2 
receptor occupancy ranges from $50 \%$ to $90 \%[3,17,18]$. At these doses, the relationship between dopamine D2 occupancy and both dose and plasma level seems to be represented by a hyperbolic saturation curve [3]. The psychopharmacological mechanism of the therapeutic response at very high doses remains unclear. Are other cerebral targets saturated at such high doses? Are receptors other than dopamine D2/D3 involved?

In conclusion, very-high-dose olanzapine seems to be a good alternative in treatment-resistant schizophrenia. Its use at such high doses needs to be closely monitored, due to poor data on its clinical and biological tolerance. Most studies suggest that the dose range is correlated with improvements in organization (lower doses) and positive symptoms (higher doses). Nevertheless, more data are needed to confirm its relative efficacy at higher doses for different symptom dimensions, compared with clozapine, in treatment-resistant schizophrenia. This could be achieved by conducting randomized double-blind trials with larger samples of participants. Furthermore, clinical data need to be correlated with imaging data in order to investigate a potential correlation between clinical improvement and the D2/D3 occupancy profile at such very high doses.

\section{REFERENCES}

[1] Bitter, I., Dossenbach, M., Brook, S., Feldman, P.D., Metcalfe, S., Gagiano, C.A., Füredi, J., Bartko, G., Janka, Z., Banki, C.M., Kovacs, G. and Breier, A. (2004) Olanzapine versus clozapine in treatment-resistant or treatmentintolerant schizophrenia. Progress in Neuropsycholopharmacology and Biological Psychiatry, 28, 173-180.

[2] Mcilwain, M., Harrison, J., Wheeler, A.J. and Russell, B. R. (2011) Pharmacotherapy for treatment-resistant schizophrenia. Neuropsychiatric Disease and Treatment, 7, 135149.

[3] Kapur, S., Zipursky, R.B., Remington, G., Jones, C., DaSilva, J., Wilson, A.A. and Houle, S. (1998) 5-HT2 and D2 receptor occupancy of olanzapine in schizophrenia: A PET investigation. American Journal of Psychiatry, 155, 921-928.

[4] Callaghan, J.T., Bergstrom, R., Ptak, L.R., and Beasley, C.M. (1999) Olanzapine: Pharmacokinetic and pharmacodynamic profile. Clinical Pharmacokinetics, 37, 177-193. doi:10.2165/00003088-199937030-00001

[5] Sheitman, B., Lindgren, C., Early, J. and Sved, M. (1997) High-dose olanzapine for treatment-refractory schizophrenia. American Journal of Psychiatry, 154, 1626.

[6] Quadri, S.F., Padala, P.R., Strunk, J.C. and Boust, S.J. (2006) High-dose olanzapine orally disintegrating tablets for treatment-resistant psychosis. The Journal of Clinical Psychiatry, 8, 244-245.

[7] Reich, J. (1999) Use of high-dose olanzapine in refractory psychosis. American Journal of Psychiatry, 156, 661 .
[8] Kumra, S., Kranzler, H., Gerbino-Rosen, G., Kester, H.M., De Thomas, C., Kafantaris, V., Correll, C.U. and Kane, J.M. (2008) Clozapine and "high dose" olanzapine in refractory early-onset schizophrenia: A 12-week randomized and double-blind comparison. Biological Psychiatry, 63, 524-529. doi:10.1016/j.biopsych.2007.04.043

[9] Meltzer, H., Bobo, W., Roy, A., Jayathilake, K., Chen, Y., Ertugrul, A., Anil Yagcioglu, A.E. and Small, J.G. (2008) A randomized, double-blind comparison of clozapine and high dose olanzapine in treatment-resistant patients with schizophrenia. The Journal of Clinical Psychiatry, 69, 274285. doi:10.4088/JCP.v69n0214

[10] Baldacchino, A.M., Stubbs, J.H. and Nevison-Andrews, D. (1998) The use of olanzapine in non-compliant or treatment-resistant clozapine populations in hospital. Pharmaceutical Journal, 260, 207-209.

[11] Dursun, S., Gardner, D., Bird, D. and Flinn, J. (1999) Olanzapine for patients with treatment-resistant schizophrenia: A naturalistic case-series outcome study. Canadian Journal of Psychiatry, 44, 701-704.

[12] Martin, J., Gomez, J.C., Garcia-Bernardo, E., Cuesta, M., Alvarez, E. and Gurpegui, M. (Spanish Group for the Study of Olanzapine in Treatment-Refractory Schizophrenia Spain) (1997) Olanzapine in treatment-refractory schizophrenia: Results of an open label study. Journal of Clinical Psychiatry, 58, 479-483. doi:10.4088/JCP.v58n1103

[13] Rodriguez-Perez, V., Lopez, A., Blanco, C., Pena, C., Lopez, A., Gomez, Y., Ferreiro, M.J., Rego, C., Lopez, A., Cudeiro, F., Alvarez, V., Prieto, R. and Ciudad, A. (2002) Olanzapine for the treatment of chronic refractory schizophrenia: A 12-month follow-up naturalistic study. Progress in Neuropsycholopharmacology and Biological Psychiatry, 26, 1055-1062.

[14] Perry, P.J., Lund, B.C., Sanger, T. and Beasley, C. (2001) Olanzapine plasma concentrations and clinical response: Acute phase results of the North American Olanzapine Trial. Journal of Clinical Psychopharmacology, 21, 1420. doi:10.1097/00004714-200102000-00004

[15] Mauri, M.C., et al. (2005) Clinical outcome and olanzapine plasma levels in acute schizophrenia. European Psychiatry, 20, 55-60. doi:10.1016/j.eurpsy.2004.09.009

[16] Lane, H.-Y., et al. (2002) Effects of olanzapine plasma concentrations on depressive symptoms in schizophrenia: A pilot study. Journal of Clinical Psychopharmacology, 22, 530-532. doi:10.1097/00004714-200210000-00019

[17] Raedler, T.J., Knable, M.B., Lafargue, T., Urbina, R.A., Egan, M.F., Pickar, D. and Weinberger, D.R. (1999) In vivo determination of striatal dopamine D2 receptor occupancy in patients treated with olanzapine. Psychiatry Research: Neuroimaging Section, 90, 81-90. doi:10.1016/S0925-4927(99)00010-4

[18] Moresco, R.M., Cavallaro, R., Messa, C., Bravi, D., Gobbo, C., Galli, L., Lucignani, G., Colombo, C., Rizzo, G., Velona, I., Smeraldi, E. and Fazio, F. (2004) Cerebral D2 and 5-HT2 receptor occupancy in schizophrenic patients treated with olanzapine or clozapine. Journal of Psychopharmacology, 18, 355-365. 